\title{
Peroxyoxalate Chemiluminescence Determination of Polyamines Using On-Line Combination of High-Performance Liquid Chromatography and an Immobilized Enzyme Column Reactor
}

\author{
Mitsuhiro Wada, Naotaka Kuroda, Toshihiko Ikenaga, Shuzo AkIYama \\ and Kenichiro NAKASHIMA ${ }^{\dagger}$
}

School of Pharmaceutical Sciences, Nagasaki University, Bunkyo-machi, Nagasaki 852, Japan

Keywords Polyamines, immobilized enzyme column reactor, high-performance liquid chromatography, peroxyoxalate chemiluminescence determination

Polyamines such as putrescine (Put), cadaverine (Cad), spermidine (Spd) and spermine (Spm) are ubiquitous nitrogen compounds found in animals, plants and microorganisms. In plants, the polyamines play an important role in membrane stabilization, free radical scavenging and synthesis of DNA, RNA and protein. ${ }^{1}$ The amount of polyamines in plants is informative about extent of the damage of plants by acid rain ${ }^{2}$, or about the freshness of food. ${ }^{3}$ In clinical chemistry, the high urinary excretion of polyamines in cancer patients made them a candidate as tumor markers.

Consequently, many analytical methods have been developed for the sensitive determination of polyamines. In high-performance liquid chromatographic (HPLC) methods, UV detection with benzoylchloride ${ }^{2,4}$, and fluorescence detection with dansyl chloride ${ }^{5}$, 9-fluorenylmethyl chloroformate ${ }^{6}$ and $o$-phthaldialdehyde ${ }^{7}$ have been reported. On the other hand, some methods utilizing an enzymic reaction have also been developed. In these, a flow injection analysis (FIA) method $^{8}$ with luminol chemiluminescence (CL) detection, and HPLC methods with peroxyoxalate chemiluminescence (POCL) ${ }^{9}$ and an electrochemical detection ${ }^{10}$ are employed. Among these, HPLC method attained high sensitivity with PO-CL detection using putrescine oxidase (PUO) and diamine oxidase as immobilized enzyme column reactors (IMERs) ${ }^{9}$, but it did not include the separation of acetyl polyamines.

More recently, we have shown that the PO-CL method is suitable for highly sensitive determinations of hydrogen peroxide ${ }^{11}$, oxidase activities ${ }^{12}$ and substrates for oxidases. ${ }^{13}$ In this paper, a sensitive and selective determination of polyamines and their mono-acetyl derivatives will be described using an IMER coimmobilized with acetylpolyamine amidohydrolase

† To whom correspondence should be addressed.
(APH) and PUO followed by an HPLC separation. Further, the method was applied to the determination of polyamines in plants to evaluate the applicability to the biological samples.

\section{Experimental}

\section{Chemicals}

Put, Cad, Spd, Spm, sodium azide and glutaraldehyde were obtained from Wako Pure Chemical Co. (Osaka, Japan). Acetyl putrescine (AcPut), acetyl cadaverine (AcCad), $N_{1}$-acetyl spermidine ( $N_{1}$-AcSpd), $N_{8}$-acetyl spermidine ( $N_{8}$-AcSpd) and acetyl spermine (AcSpm) used were from Sigma Chemical Co. (St. Louis, MO, USA). PUO from pseudomonas with $15 \mathrm{U} / \mathrm{mg}$ was obtained from Toyobo Co. (Tokyo, Japan) and APH from mycoplana bullata with $12.5 \mathrm{U} / \mathrm{mg}$ was kindly donated by Kyowa Medics Co. (Tokyo, Japan). Aminopropyl-controlled pore glass (particle size, 125 $177 \mu \mathrm{m}$; pore diameter, $500 \AA$; Pierce Chemicals Co., Rockford, IL, USA) was used to immobilize the enzymes. Sodium octanesulfonate (SOS) and bis $(2,4,6$ trichlorophenyl)oxalate (TCPO) were obtained from Tokyo Kasei Kogyo Co. (Tokyo, Japan) and 2,4,6,8tetrathiomorpholinopyrimido[5,4-d]pyrimidine (TMP) was synthesized by our previous method. ${ }^{14}$ Water was deionized and passed through the Pure Line WL $21 \mathbf{P}$ system (Yamato Scientific Co., Tokyo, Japan). The other chemicals used were of analytical reagent grade.

\section{HPLC system}

The HPLC system consists of three HPLC pumps (LC6A, Shimadzu, Kyoto, Japan), a 7125 injector with $10-\mu 1$ sample loop (Rheodyne, Cotati, CA, USA), a separation column (Asahipak ODP-50, $250 \times 4.6 \mathrm{~mm}$, i.d., $5 \mu \mathrm{m}$, Asahi Chemical Industry Co., Tokyo, Japan), a column 


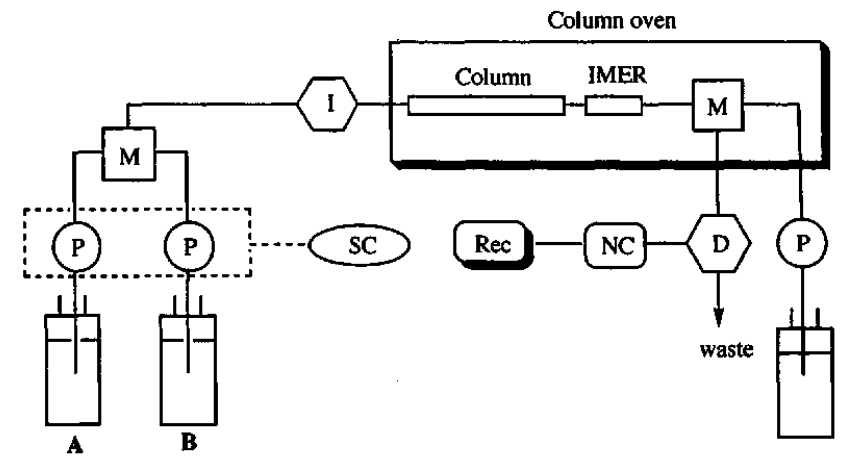

Fig. 1 HPLC system used for the determination of polyamines. $P$, pump; $I$, injector with $10-\mu$ l sample loop; IMER, immobilized enzyme column reactor $(70 \times 2 \mathrm{~mm}$, i.d.); D, detector; M, mixing device; NC, noise cleaner; Rec, recorder; SC, system controller.

oven (CTO-6AS, Shimadzu), a CL detector (CLD-10A, Shimadzu), a system controller (SCL-6A, Shimadzu), a noise cleaner (Uni-1, Union Co., Gunma, Japan) and a recorder (FBR-1, Tosoh, Tokyo, Japan). A schematic diagram of the system is shown in Fig. 1. For the separation of polyamines, $0.1 \mathrm{M}$ (eluent $\mathrm{A}$ ) and $0.25 \mathrm{M}$

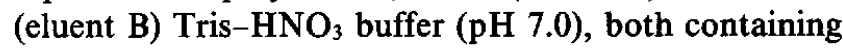
$0.5 \mathrm{mM}$ sodium azide and $2 \mathrm{mM}$ SOS, were used as eluents. Eluent $\mathrm{A}$ was pumped for $22 \mathrm{~min}$ and then quickly changed to eluent $B$. Both eluents were flowed at $0.8 \mathrm{ml} / \mathrm{min}$. A mixture of $0.4 \mathrm{mM} \mathrm{TCPO}$ and $1.0 \mu \mathrm{M}$ TMP in acetonitrile was used as a CL reagent and flowed at $1.0 \mathrm{ml} / \mathrm{min}$.

\section{Preparation of immobilized enzyme column reactor}

The IMER was prepared by the glutaraldehyde method $^{15}$ as follows; $100 \mathrm{mg}$ of aminopropyl-controlled pore glass beads suspended in $5 \mathrm{ml}$ of $2.5 \%$ glutaraldehyde aqueous solution were stirred for $1 \mathrm{~h}$ at room temperature and then washed three times with $5 \mathrm{ml}$ of $50 \mathrm{mM}$ phosphate buffer (pH 7.5). Then the glass beads were resuspended in $1 \mathrm{ml}$ of the same buffer containing $5 \mathrm{mg}$ of APH and PUO each, and allowed to stand for $12 \mathrm{~h}$ at $4^{\circ} \mathrm{C}$. After removing the supernatant, the beads were washed three times with the phosphate buffer and packed in a stainless-steel column $(70 \times 2 \mathrm{~mm}$, i.d.) by suction with a syringe. The IMER was kept in a refrigerator in $50 \mathrm{mM}$ phosphate buffer ( $\mathrm{pH} 7.5$ ) until use.

\section{Determination of polyamines in plants}

Potatoes, mini-tomatoes and tomatoes were purchased from the market. As polyamines are known to be adsorbed on glass surfaces, polystyrene tubes were used to prepare and store their sample solutions. Sample plants were treated as follows for the measurement of polyamines. A sliced potato $(6 \mathrm{~g})$, a whole mini-tomato $(c a .16 \mathrm{~g})$ and a cut tomato $(\mathrm{ca} .20 \mathrm{~g})$ were individually homogenized with $3 \mathrm{ml}$ of water by a Waring blender at $15000 \mathrm{rpm}$ for $5 \mathrm{~min}$ in an ice bath. The homogenate spiked with standard polyamines was diluted with water to $15 \mathrm{ml}$ for potato, $30 \mathrm{ml}$ for mini-tomato and $40 \mathrm{ml}$ for tomato. A 50- $\mu \mathrm{l}$ of $0.5 \mathrm{M}$ perchloric acid was added to a 950- $\mu 1$ of diluted homogenate and mixed well; the resultant mixture was allowed to stand for $1 \mathrm{~h}$ in an ice bath. After centrifugation at $2000 \mathrm{~g}$ for $10 \mathrm{~min}$, a $250-\mu \mathrm{l}$ of supernatant was pipetted, neutralized with $15-\mu 1$ of $1.0 \mathrm{M} \mathrm{NaOH}$ and diluted with $235 \mu \mathrm{l}$ of eluent $\mathrm{A}$. The resultant solution was passed through a membrane filter $(0.45 \mu \mathrm{m})$ and stored at $-20^{\circ} \mathrm{C}$ until use. A $10-\mu \mathrm{l}$ portion of this solution was injected into the HPLC system.

\section{Results and Discussion}

\section{Preparation of immobilized enzyme column reactor}

At first, two types of columns immobilized with enzymes were tested: i.e., an IMER co-immobilized with APH and PUO, and a tandem IMER immobilized with an individual enzyme. The $C L$ intensity yielded by the former for each Cad, Spd, $N_{1}-\mathrm{AcSpd}$ and $N_{8}-\mathrm{AcSpd}$ was 3 times higher than the latter, and thus the IMER coimmobilized with APH and PUO was selected for further experiments. This result was similar to that obtained with cholesterol ester hydrolase and cholesterol oxidase. ${ }^{16}$ The stability of the co-immobilized IMER with APH and PUO was tentatively measured as a function of the peak height for AcPut. The peak heights were almost constant for 100 runs, and then gradually decreased; the peak height at the 250th run was about $80 \%$ of that of the initial run.

\section{HPLC conditions}

Three types of commercially available columns (ODS, $\mathrm{C}_{8}$, aminopropyl-modified silica gel) were preliminary examined to separate polyamines. Satisfactory separations could not be attained with these columns. Therefore, an ODP column, which was reported to give a good separation of some polyamines ${ }^{10}$, was used for further experiments with some modifications of the separation conditions. A $20 \mathrm{mM}$ imidazole- $\mathrm{HNO}_{3}$ buffer ( $\mathrm{pH}$ 7.0), $0.2 \mathrm{M}$ phosphate buffer ( $\mathrm{pH}$ 7.7), $0.1 \mathrm{M}$ Tris- $\mathrm{HNO}_{3}$ buffer $(\mathrm{pH} 7.0)$ and $50 \mathrm{mM}$ Veronal- $\mathrm{HNO}_{3}$ buffer (pH 8.0) were examined as eluents. The imidazole and Veronal buffers, which are available for determining oxidase activities with PO-CL detection ${ }^{12}$, could not separate polyamines. On the other hand, the Tris- $\mathrm{HNO}_{3}$ buffer showed the best separation of polyamines, and gave stronger $C L$ intensities than those with phosphate buffer. Since the effect of $\mathrm{pH}$ (ranging from 6.8 to 7.7) of $0.2 \mathrm{M}$ Tris- $\mathrm{HNO}_{3}$ buffer on the separation of polyamines was very small, $\mathrm{pH} 7.0$ providing the maximal $\mathrm{CL}$ intensities was chosen. The addition of SOS to the eluent improved the separation of polyamines. The retention time was prolonged with increasing the SOS concentration from 0 to $5 \mathrm{mM} ; 2 \mathrm{mM}$ SOS showing a good separation was chosen. Although $0.1 \mathrm{M}$ Tris- $\mathrm{HNO}_{3}$ buffer as an eluent showed the best separation, it took more than $150 \mathrm{~min}$ for the complete 


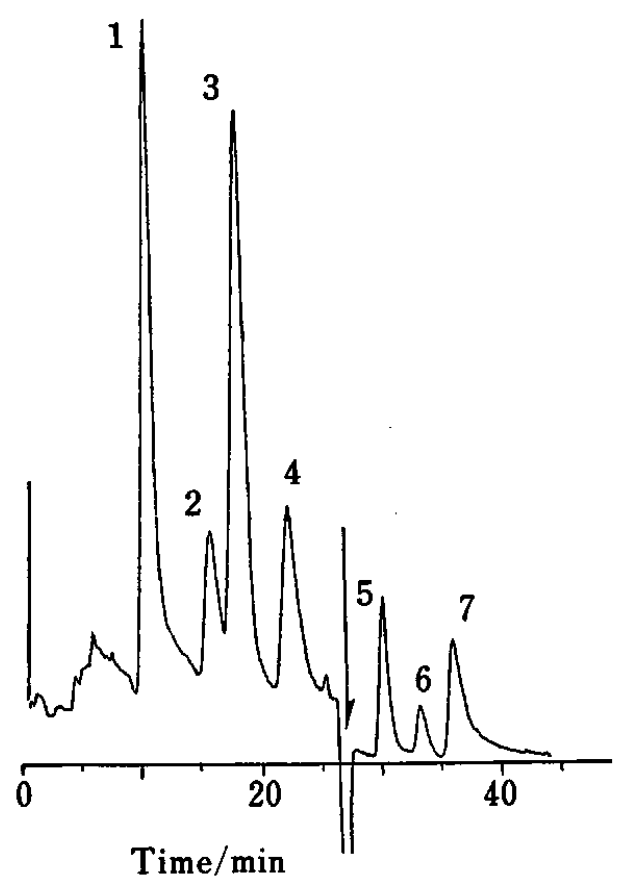

Fig. 2 Chromatogram of the standard polyamines. Sample: Put, AcPut $=250 \mathrm{pmol} /$ injection; Cad, AcCad, Spd, $N_{1}-\mathrm{AcSpd}$ and $N_{8}-\mathrm{AcSpd}=500 \mathrm{pmol} /$ injection; peaks: $1=$ AcPut, $2=$ AcCad, $3=$ Put, $4=\mathrm{Cad}, 5=N_{1}$-AcSpd, $6=N_{8-}$ AcSpd and $7=$ Spd. The arrow indicates the changing of the eluents. Sensitivity: 5.0 nAFS. Other HPLC conditions are as in the Experimental.

elution of the seven polyamines. By changing the Tris concentration instantly from $0.1 \mathrm{M}$ to $0.25 \mathrm{M}$ at $22 \mathrm{~min}$ after sample injection, the separation of polyamines was attained within $40 \mathrm{~min}$. The retention times of the polyamines were as follows: $9.8 \mathrm{~min}$ for AcPut, $15.3 \mathrm{~min}$ for AcCad, $17.5 \mathrm{~min}$ for Put, $21.8 \mathrm{~min}$ for Cad, $29.5 \mathrm{~min}$ for $N_{1}$-AcSpd, $32.8 \mathrm{~min}$ for $N_{8}$-AcSpd and $35.5 \mathrm{~min}$ for Spd. The typical chromatogram of standard polyamines is shown in Fig. 2. As Spm and AcSpm were hard to convert to hydrogen peroxide because of the low specificity of PUO to Spm on the IMER, these compounds were excluded from the targets tentatively. Other polyamine oxidases should be used for the sensitive determination of Spm and AcSpm.

Since sodium azide can enhance PO-CL intensity ${ }^{17}$, the effect of its concentration on $\mathrm{CL}$ intensity in our system was examined; $0.5 \mathrm{mM}$ sodium azide in the eluent gave the largest CL intensity without any effect on the separation of polyamines.

A mixture of TCPO and TMP as a CL reagent was used in this system because we showed that it gives an intense CL. ${ }^{12}$ The effects of the concentrations of TCPO and TMP on CL intensities were examined. The CL intensities increased with an increase in the concentrations of both TCPO and TMP, but noise levels also increased. The mixture of $0.5 \mathrm{mM}$ TCPO and $1.0 \mu \mathrm{M}$ TMP giving the largest signal-to-noise ratio $(S / N)$ was selected. The effect of flow rate of the CL reagent on $C L$ intensity was also examined. The CL intensity increased with an increase in the flow rate from 0.6 to $1.4 \mathrm{ml} / \mathrm{min} ; 1.0 \mathrm{ml} / \mathrm{min}$ showed the largest $S / N$ and thus was selected. The temperature of a column oven, in which a separation column and an IMER were placed, was examined by changing the degree from 25 to $35^{\circ} \mathrm{C}$. An increase in temperature had almost no effect on the separation of polyamines, but the maximum CL intensity was observed at $35^{\circ} \mathrm{C}$.

\section{Calibration curve, detection limit and precision}

The good linearities of the relationships between the concentrations of polyamines and the $C L$ intensities were obtained $(r>0.989)$ in the concentration range of $25-$ 500 pmol for Put and AcPut, and 50-1000 pmol for Cad, AcCad, Spd, $N_{1}$-AcSpd and $N_{8}$-AcSpd. The equations obtained were as follows: $y=0.127 x-0.183$ for Put, $y=0.201 x+0.278$ for AcPut, $y=0.042 x-0.055$ for Cad, $y=0.030 x-0.850$ for AcCad, $y=0.013 x+0.466$ for Spd, $y=0.032 x-0.392$ for $N_{1}$-AcSpd and $y=0.017 x-0.786$ for $N_{8}$-AcSpd. In these equations, $x$ is the concentration of polyamine (pmol/10 $\mu$ l injection) and $y$ is $C L$ intensity (arbitrary unit). The detection limits were 5 pmol for Put, 2 pmol for AcPut, 15 pmol for Cad, 20 pmol for AcCad, 20 pmol for Spd, 12 pmol for $N_{1^{-}}$ AcSpd and 25 pmol per injection for $N_{8}$-AcSpd at $S / N$ of 3. The sensitivity of the proposed method was 6 times higher than that of the FIA-luminol CL method $^{8}$ with respect to Put, and comparable to that of the PO-CL method. ${ }^{9}$ The RSDs of CL intensities with 5 replicate measurements of $250 \mathrm{pmol}$ Put and AcPut, and $500 \mathrm{pmol}$ Cad, AcCad, Spd, $N_{1}$-AcSpd and $N_{8}$-AcSpd were 3.3, $2.8,2.9,4.6,7.8,6.6$ and $7.8 \%$, respectively.

\section{Determination of polyamines in plants}

The polyamine contents of potato, mini-tomato and tomato were determined by a standard addition method; three different amounts of standard polyamines were added to plants. Put $(150-1500 \mathrm{nmol})$ and Spd (300$1500 \mathrm{nmol})$ were spiked for potato, Put $(40-400 \mathrm{nmol})$ was spiked for mini-tomato and tomato. The determination of each sample was performed three times. The mean amounts of Put and Spd found in five potatoes were $121.5 \pm 80.5$ and $51.0 \pm 24.3 \mathrm{nmol} / \mathrm{g}$ wet weight, respectively. These levels are in good agreement with those reported previously. ${ }^{18}$ In mini-tomato and tomato, only Put was detected; the amounts for each of five samples were $11.2 \pm 3.4$ and $8.2 \pm 3.9 \mathrm{nmol} / \mathrm{g}$ wet weight, respectively. The RSDs for within-day $(n=3)$, and between-day assays for a week $(n=3)$ were determined for potato samples spiked with Put and Spd (125 and $250 \mathrm{nmol} / \mathrm{g}$ wet weight) as shown in Table 1 . The accuracy of the method was also examined using potato samples spiked with known concentrations of standard polyamines (Table 2). The percentages of nominal were found to be $>93 \%$. These results showed that the 
Table 1 Between-day and within-day precisions of assays for polyamines spiked in potato

\begin{tabular}{cccc}
\hline Compound & $\begin{array}{c}\text { Amount added } \\
\text { (nmol/g wet } \\
\text { weight) }\end{array}$ & $\begin{array}{c}\text { Within-day } \\
(n=3) \\
\text { RSD, } \%\end{array}$ & $\begin{array}{c}\text { Between-day } \\
(n=3) \\
\text { RSD, \% }\end{array}$ \\
\hline Put & 125 & 5.1 & 7.6 \\
& 250 & 5.2 & 7.3 \\
Spd & 125 & 8.3 & 10.7 \\
& 250 & 5.9 & 6.5 \\
\hline
\end{tabular}

Table 2 Accuracy of assay for polyamines spiked in potato

\begin{tabular}{cccc}
\hline Compound & $\begin{array}{c}\text { Amount added } \\
\text { (nmol/g wet } \\
\text { weight) }\end{array}$ & $\begin{array}{c}\text { Amount found } \\
\text { (means } \pm \text { SD) } \\
\text { (nmol/g wet } \\
\text { weight) }\end{array}$ & $\begin{array}{c}\text { Percentage } \\
\text { of nominal, } \\
\%\end{array}$ \\
\hline Put & 125 & $111.5 \pm 6.9$ & 89.2 \\
Spd & 250 & $231.3 \pm 9.2$ & 92.4 \\
& 125 & $118.7 \pm 15.7$ & 95.0 \\
& 250 & $236.8 \pm 27.4$ & 94.7 \\
\hline
\end{tabular}

a. $n=4$.

proposed method is suitable for the determination of polyamines. As the proposed method is simple, specific and sensitive, it should be useful for the determination of polyamines in other biological samples.

We thank Kyowa Medics Co. for providing acetylpolyamine amidohydrolase.

\section{References}

1. A. F. Tiburcio, J. L. Campos, X. Figueras and R. T. Besford, Plant Growth Regul., 12, 331 (1993).

2. M. Tenter and A. Wild, J. Plant Physiol., 137, 647 (1991).

3. J. L. Mietz and E. Karmas, J. Food Sci., 42, 155 (1977).

4. K. Kotzabasis, M. D. C. Hampsas and K. A. Roubelakis, Anal. Biochem., 214, 484 (1993).

5. M. Marce, D. S. Brown, T. Capell, X. Figueras and A. F. Tiburcio, J. Chromotogr. B, 666, 329 (1995).

6. G. Huhn, J. Mattusch and H. Schulz, Fresenius J. Anal. Chem., 351, 563 (1995).

7. S. Watanabe, S. Sato, S. Nagase, M. Tomita, S. Saito and H. Ishizu, J. Liq. Chromatogr., 16, 619 (1993).

8. S. Kamei, F. Mashige, A. Ohkubo, M. Yamanaka, M. Okada, Y. Yoshimura and K. Imahori, Jap. J. Clin. Chem., 13, 66 (1984).

9. S. Kamei, A. Ohkubo, S. Saito and S. Takagi, Anal. Chem., 61, 1921 (1989).

10. K. Hiramatsu, S. Kamei, M. Sugimoto, K. Kinoshita, K. Iwasaki and M. Kawakita, J. Biochem., 115, 584 (1994).

11. K. Nakashima, M. Wada, N. Kuroda, S. Akiyama and K. Imai, J. Liq. Chromatogr., 17, 2111 (1994).

12. K. Nakashima, N. Kuroda, S. Kawaguchi, M. Wada and S. Akiyama, J. Biolumin. Chemilumin., 10, 185 (1995).

13. M. Wada, K. Nakashima, N. Kuroda, S. Akiyama and $K$. Imai, J. Chromatogr. B., 678, 129 (1996).

14. K. Nakashima, S. Akiyama, Y. Tsukamoto and K. Imai, Dyes Pigm., 12, 21 (1990).

15. J. Endo, M. Tabata, S. Okada and T. Murachi, Clin. Chim. Acta, 95, 411 (1979).

16. M. Tabata, J. Endo and T. Murachi, J. Appl. Biochem., 3, 84 (1981).

17. S. K. Oh and S. H. Cha, Anal Biochem., 218, 222 (1994).

18. R. K. Sawhney, L. M. Shin and A. W. Galston, Plant Physiol., 69, 411 (1982). 